\title{
Water first: issues and challenges for nations and communities of South Asia
}

\author{
Kuntala Lahiri-Dutt and Robert Wasson (editors) \\ Delhi: Sage Publications, 2008
}

Reviewed by Ashok Jaitly, Distinguished Fellow, TERI

Resources, Energy, and Development 6(1): 45-47

The title of this volume is truly emphatic. For South Asia, Water first is truly apt if we are to seriously consider a sustainable future for the region. Being a predominantly agriculture- and rural-based society, all else will become secondary, unless water issues are addressed conclusively. What makes the issue even more preeminent for the entire region is the commonality of the water source, along with the commonality of its usage and the commonality of its increasing scarcity.

As editor Kuntala Lahiri-Dutt states in the Introduction chapter, 'Water is a unique resource, appearing in different forms and shaping all physical and biological processes. Known for its fluidity and celebrated for changing its shape... water also plays a special role in social and cultural representations... reflected in the ways water is perceived, used, governed and treated.' In this volume, she and co-editor Robert Wasson have put together a set of articles that focus on several cross-cutting issues and challenges being faced by the nations and diverse communities of South Asia, with a particular emphasis on India. It has also been very appropriately emphasized that the dialogue on water issues needs to be much more inclusive among the so-called 'water experts' and 'social concerns' in order to promote a 'holistic understanding of this vital natural element'. In a sense, this is going beyond the earlier concern that there is an imperative need to shift the water dialogue from the exclusive confines of the engineering fraternity to a broad-based multidisciplinary community. This comes through as a recurring theme throughout the book.

The book is divided into three sections, with the first section dealing with the regional politics of water, the second with regional issues and challenges, and the third with community roles and initiatives. Inevitably, there is an overlap between the sections, which need not, therefore, be taken as excessively distinct aspects. In fact, each chapter can be read as an internally coherent analysis of a specific issue.

Consequently, there is a variation in the perspective as well as the scope and quality of analysis.

The first chapter by the doyen of Indian water experts, Ramaswamy R Iyer, provides a sweeping overview of the major water issues at the national and regional levels and pleads for greater collaboration amongst countries but not necessarily confined to governments and largescale 'multi-purpose' projects. As usual, Iyer's account is not only comprehensive, covering a wide range of subjects, but also somewhat diluted. Avijit Gupta goes on to offer a geomorphologic perspective on river management and argues for more studies on water flows and the environmental impacts of 
undertaking major interventions like the interbasin transfers being proposed in countries like China and India. This finds a sympathetic echo in the chapter on river linking by Rohan D'Souza. There can be no two opinions on the need to strengthen the database on water issues in the region, and it is a matter of regret that despite the gravity of the situation, the institutional infrastructure for indepth study of the sector continues to be extremely weak.

An extremely interesting and significant conclusion that emerges out of several of chapters is that historically, water has had and continues to have a strong political dimension in terms of social and economic control within and among communities. David Hardiman traces this from very early times of the colonial era, while Douglas Hill deals with the current dynamics among India, Pakistan, Bangladesh, and Nepal. This is put into a wider international context by Binayak Ray, who also emphasizes the growing importance of China's role through its control over the water sources in Tibet. The potential of water becoming a major source of regional conflict in South Asia cannot, therefore, be understated and needs to be addressed through an effective multilateral mechanism because the bilateral approach followed so far does not seem to be yielding very positive outcomes. Once again, the need for far greater cooperation at the political, official, scientific, and community levels is too obvious to be laboured.

The availability of water and its sectoral allocation has always had a direct link with economic growth and social development through either agriculture or industry, including the production of energy. The articles by Robert Wasson, Bruce Caldwell, and Atanu Sarkar attempt to explore yet another important linkage between water quality, community health, and productivity. The serious incidences of occurrence of arsenic in

Bangladesh and eastern India as well as the many water-borne diseases are not only matters of deep human concern but clearly impact on the productive capacity of society as a whole. In many cases, satisfactory solutions have not been found despite considerable investment in scientific and financial resources.

Governance and management of water resources are examined from different perspectives by Sara Ahmed (gender issues), Vishal Narain and Saurabh Chugh (institutions), Saravanan (community participation), and Sucharita Sen (watershed development), all of whom argue for a change in the conventional engineer-centric strategies of water management, which have been pursued in all the countries of the region. Even while there has been growing recognition and indeed acceptance of IWRM (integrated water resource management), river basin management approach, PRM (participatory resource management), and CBWM (community-based watershed management) as superior and more effective strategies, these have not been operationalized to the extent required, primarily because of the strongly entrenched vested interests within the socio-political and administrative strictures. A number of NGOs have demonstrated the effectiveness of alternative paradigms but their upscaling, replication, and mainstreaming into government programmes still remain difficult tasks. Here, civil society has a critical advocacy role to play in generating debate and pressurizing policymakers.

Even though the Introduction chapter recognizes that the volume has 'a particular emphasis on India', the case studies on different aspects in the final section are predominantly drawn from Indian experiences, which does detract from the wider regional perspective. This also perhaps reflects the observation made earlier in this review that there is considerable scope for increasing the interaction between the scientific community and civil society within the region. This needs to go beyond participation in conferences and seminars and extend into joint research studies, exchange of knowledge, and 
institutional linkages. There is also something of a discontinuity in the selection of subjects in the volume in as much as the spectrum, which is perhaps too broad to provide a focused picture of the linkages in the water sector between nations and communities in the region. Without a more detailed understanding of these interdependencies, it would be difficult to come up with a comprehensive perspective, leave alone an integrated programme of action that could be concretely pursued. For too long, we have kept the debate at too generalized a level. Nevertheless, there is no doubt that the volume is a welcome addition to the growing literature on analysing water issues in South Asia within an interdisciplinary framework and hopefully would generate more specific collaborative studies in the future. 